\title{
Predictive and prognostic factors
}

\author{
Mitch Dowsett*
}

The goal of personalised medicine is a top priority for current clinical research and in the UK this has been recognised by the development of a Stratified Medicines Initiative, which is being led by the Medical Research Council. Although oncology is unique among disciplines in its personalisation, being markedly influenced by somatic mutations, it is expected to be in the vanguard of developments under this initiative. Given that breast cancer is the most advanced malignancy in terms of biomarkers and molecular signatures used for stratification of treatment, it is a key disease for inclusion in this initiative. The communications in this section of the meeting report are therefore particularly timely. The papers are separated to deal with two main issues. Firstly, what are the opportunities, constraints and requirements for the establishment of predictive and prognostic factors that have clinical utility, and are there new ways in which we can integrate these into a pathological understanding of the disease? Secondly, does molecular profiling currently offer any more than tumour histology or basic immunochemistry for clinical application?

Dr Hayes considers the manner in which we should develop biomarkers and the emphasis that should be placed upon them to elicit maximum value. The overall theme is that a bad biomarker is as bad as a bad drug. To this a subtext can be added: a good biomarker can at times make a poor drug good (at least in a subset of patients), and a bad biomarker can also make a good drug bad by guiding treatment inaccurately. The most important issue is that we should be placing the same resources and rigour behind marker development as we do the development of drugs: current expenditure and effort are badly out of proportion to the relative importance of biomarkers.

It has taken many years to create authoritative guidelines for the conduct of HER2 diagnostics, and even longer for those guiding steroid receptor analyses; however, the recent alliance of oncologists from

*Correspondence: mitch.dowsett@icr.ac.uk

Academic Department of Biochemistry, Biochemical Endocrinology and the Breakthrough Research Centre, Royal Marsden Hospital, Fulham Road, London, SW3 6JJ, UK
American Society of Clinical Oncology and pathologists from the College of American Pathologists has created guidelines $[1,2]$ that will hopefully improve the accuracy, precision and consistent interpretation of these tests, which have enormous importance for selecting appropriate therapy. While it will take some time for full guidelines to be developed for new markers, it is appropriate that those involved in the assessment of highly encouraging emergent markers should meet early and gather best evidence for harmonisation of approaches to analysis, scoring and reporting, such that comparability between their assessments can be ensured and a rapid assessment of the markers' true importance be established.

The level of evidence for bringing a marker into recommended clinical usage is rightly conservative given that inappropriate application would lead to incorrect treatment of patients. Early acquisition of such evidence requires attention to good study design and validity of methodology. In the past it has been felt necessary to have a prospective clinical study that demonstrates unequivocally the value of a marker in stratifying patient therapy; however, Simon and colleagues [3] recently concluded that level one evidence may be obtained from two independent retrospective/prospective analyses that are sufficiently powered and separately confirm the biomarker-led separation of groups of differing outcome.

Unfortunately, at the present time, the value of tumour biomarkers appears to be underestimated and certainly under-funded: the diagnostics market is massively outweighed by the therapeutics market in oncology. Nonetheless, recent initiatives to identify the costs that may be saved by appropriate application of a new diagnostic are beginning to allow the application of markers that look expensive compared to those in the past, but in fact reflect the investment required for rigorous quality control and high reproducibility.

Dr Mills considers the bias and artefacts that may occur both in the preclinical laboratory and in molecular pathology laboratories assessing clinical specimens. A number of factors influence this: the requirement for separate training and test sets of samples has been well established in clinical studies but is less well applied in molecular biology. In the clinical laboratory it is becoming clear that while some markers are relatively resistant to degradation in the time that fixation occurs by 
formalin or other preservatives, certain markers are much more labile. Evidence for this has recently been gathered from an assessment of pERK and pAKT in corecut biopsies and pieces of surgical excisions taken at the time of operation or subsequent to routine fixation [4]. Striking and consistently lower values for each of these markers were found in excision biopsies, and it seems almost certain that this is due to the slow penetrance of formalin into tissues (approximately $1 \mathrm{~mm}$ per hour) and, therefore, the opportunity for loss of marker integrity. The actual preservation in excision biopsies is likely to reflect the protocols that are used for fixing tumours in different establishments. Thus, substantial analytical noise may be introduced into assessments of these and similarly affected markers in excision biopsies and will affect studies by tissue microarray analysis, which are being increasingly used for clinical research. The degradation that may have occurred to an unknown degree through the excision biopsies must, therefore, be recognised as potentially leading to false negative results. It should also be noted that false positive results might be apparent if, for example, core cuts were compared with sections of an excision biopsy in a short term 'window of opportunity' study: the apparent reduction in PAKT and pERK could, in these circumstances, be read as evidence of therapeutic efficacy.

Heterogeneity of biomarkers is becoming increasingly recognised to occur at numerous levels, including different mutations across a single tumour as well as between lesions in a single patient. This provides challenges to the concept of personalised medicine where the biology of different lesions or within a lesion may be highly variable. Overall, it is helpful to regard all of the measures that we make in molecular pathology or immunohistochemistry to be artefactual in some manner: the way in which that artefact is measured should be considered in the context of its fitness for the purpose to which it will be applied.

Alongside these complications to the consistent measurement of biomarkers, Dr Faratian considers the new science of systems biology and the potential to extend this to systems pathology. In systems biology, extreme control of experimental design and output is needed to understand the impact of perturbations on the system and the regulatory systems that react to such change. It seems unreasonable to consider that this degree of control can be exerted within a clinical experimental situation. In addition, the requisite validity for an assessment of the concentration or activity of a given biological entity needed for systems biology/pathology requires precision and analytical abilities that go well beyond those required for standard biomarker analyses. Time will tell whether consideration of biological systems using biomarker measurements in biopsy tissues is a realistic possibility.
The other authors in this session deal with the question of whether these new markers offer more to the clinician than histopathology or basic biomarkers. It has been heartening over recent years to find that certain molecular profiles, most notably the Oncotype Dx Recurrence Score, have shown sufficient clinical utility that their relatively expensive nature does not prevent them from being widely applied in health systems with sufficient funding. Taking the Recurrence Score as the most relevant example, it is notable that the developers of this had a strategy that enhanced the likelihood of success. This included the identification of a clinical question of current and continuing clinical importance, that is, the identification of those oestrogen-receptor-positive patients on endocrine therapy who were node negative and whose risk of recurrence was so low as to safely exclude them from the application of cytotoxic chemotherapy. In addition, technology was developed that not only was applicable to the most widely available pathological material (formalin-fixed, paraffin-embedded blocks) but also was shown to be valid in tissues derived, in some cases, from samples taken over three decades ago. One thing that has become apparent is that the molecular information that drives the Recurrence Score is of similar magnitude to, but also differs almost entirely from, the information that is gathered from clinicopathological parameters, such as nodal status, tumour size and histo-pathological grade. Given the independence of these two measures, the opportunity to integrate these into a tool that is more powerful than either alone is attractive and has been now addressed by a collaboration of the ATAC (Arimidex, Tamoxifen, Alone or in Combination) and the NSABP (National Surgical Adjuvant Breast and Bowel Project) trialists [5].

The value of the Recurrence Score in reducing the cost of cytotoxic chemotherapy (let alone the prevention of toxicity in patients not needing the treatment) has been well-recorded, but even this to date has not been sufficient to have the test recommended by health authorities in the UK or in many other parts of the western world. The ability for standard immunohistochemical measurement of the oestrogen receptor, progesterone receptor, Ki67 and HER2 to provide at least as much prognostic information as the Recurrence Score has recently been demonstrated [6]. While this may eventually be shown to be a viable alternative, for this to be the case the standardisation that is required for routine implementation will need to be forthcoming. Thus, at the present time, molecular pathology probably does offer rather more than tumour morphology and basic immunohistochemistry, but the degree to which this is the case may frequently be overstated.

Competing interests

The author declares that they have no competing interests. 
Dowsett Breast Cancer Research 2010, 12(Suppl 4):S2

Page 3 of 3

http://breast-cancer-research.com/supplements/12/S4/S2

\section{Acknowledgements}

This article has been published as part of Breast Cancer Research Volume 12 Supplement 4, 2010: Controversies in Breast Cancer 2010. The full contents of the supplement are available online at http://breast-cancer-research.com/ supplements/12/S4

Published: 20 December 2010

\section{References}

1. Wolff AC, Hammond ME, Schwartz JN, Hagerty KL, Allred DC, Cote RJ, Dowsett M, Fitzgibbons PL, Hanna WM, Langer A, McShane LM, Paik S, Pegram MD, Perez EA, Press MF, Rhodes A, Sturgeon C, Taube SE, Tubbs R, Vance GH, van de Vijver M, Wheeler TM, Hayes DF; American Society of Clinical Oncology; College of American Pathologists: American Society of Clinical Oncology/College of American Pathologists guideline recommendations for human epidermal growth factor receptor 2 testing in breast cancer. J Clin Oncol 2007, 25:118-145.

2. Hammond ME, Hayes DF, Dowsett M, Allred DC, Hagerty KL, Badve S, Fitzgibbons PL, Francis G, Goldstein NS, Hayes M, Hicks DG, Lester S, Love R, Mangu PB, McShane L, Miller K, Osborne CK, Paik S, Perlmutter J, Rhodes A, Sasano H, Schwartz JN, Sweep FC, Taube S, Torlakovic EE, Valenstein P, Viale G, Visscher D, Wheeler T, Williams RB, et al.: American Society of Clinical

Oncology/College Of American Pathologists guideline recommendations for immunohistochemical testing of estrogen and progesterone receptors in breast cancer. J Clin Oncol 2010, 28:2784-2795.
3. Simon RM, Paik S, Hayes DF: Use of archived specimens in evaluation of prognostic and predictive biomarkers. J Natl Cancer Inst 2009, 101:1446-1452.

4. Pinhel I, MacNeill F, Hills M, Salter J, Detre S, A'Hern R, Nerurkar A, Osin P, Smith IE, Dowsett M: Extreme loss of immunoreactive p-AKT and p-ERK1/2 during routine fixation of primary breast cancer. Breast Cancer Res 2010, 12:R76.

5. Tang G, Cuzick J, Wale C, Costantino JP, Crager M, Shak S, Wolmark N, Dowsett $M$, Forbes JF: Recurrence risk of node-negative and ER-positive early-stage breast cancer patients by combining recurrence score, pathologic, and clinical information: A meta-analysis approach. J Clin Oncol 2010, 28(Suppl):509.

6. Cuzick J, Dowsett M, Wale C, Salter J, Quinn E, Zabaglo L, Howell A, Buzdar A, Forbes JF: Prognostic value of a combined ER, PgR, Ki67, HER2 immunohistochemical (IHC4) score and comparison with the GH Recurrence Score - results from Trans ATAC. Cancer Res 2009, 69(suppl):503s.

doi: $10.1186 /$ bcr 2731

Cite this article as: Dowsett M: Predictive and prognostic factors. Breast Cancer Research 2010, 12(Suppl 4):S2 